\title{
Morphometric and Molecular Analysis of the Three Arbutus Species of Greece
}

\author{
Konstantinos F. BERTSOUKLIS*, Maria PAPAFOTIOU
}

\author{
Agricultural University of Athens, School of Agriculture, Engineering and Environmental Sciences, Department of Crop Sciences, Laboratory of \\ Floriculture and Landscape Architecture, Iera Odos 75, 11855 Athens, Greece; kber@aua.gr ("corresponding author); mpapaf@aua.gr
}

\begin{abstract}
Arbutus andrachne, A. unedo and $A . \times$ andrachnoides found in the Greek macchia are promising species for reforestations, ornamental use, as well as for medicinal use and the food industry. Morphological traits and molecular markers (RAPD) were used to identify and distinguish these Arbutus species to facilitate their exploitation. Since there are no descriptors established for Arbutus spp., 23 qualitative morphological characteristics of crown, foliage, bark, flowering, fruiting, and four quantitative morphological characteristics of leaf and fruit were selected and used to define differences and similarities between sampled individuals of $A$. andrachne, $A$. unedo and individuals with intermediate characteristics sampled as $A . \times$ andrachnoides. Twenty eight individuals representative of three Arbutus taxa were sampled in two typical macchia forest areas of the prefecture of Attica, Greece. Cluster analysis based on morphological characteristics separated the individuals in three distinct groups, and this was confirmed by molecular analysis. The intermediate form was indicated as $A . \times$ andrachnoides, a natural hybrid of $A$. andrachne and $A$. unedo. Fifteen 10-mer oligonucleotide arbitrary primers used to amplify genomic DNA generated 166 reproducible polymorphic fragments, which revealed that $A . \times$ andrachnoides has higher degree of genetic similarity with $A$. andrachne than $A$. unedo. The applied morphometric characteristics are suggested as a basis to develop a complete list of discriminating descriptors for Arbutus genus.
\end{abstract}

Keywords: Arbutus spp., molecular markers, morphological traits, PCR, RAPD, strawberry tree, UPGMA

\section{Introduction}

Three Arbutus species (Arbutus andrachne L., Arbutus unedo L. and Arbutus $\times$ andrachnoides Link, f. Ericaceae), typical members of the Greek macchia, are promising for exploitation in forestry, landscape, horticulture and pharmaceutical industry. $A$. unedo (strawberry tree) and $A$. andrachne (Eastern or Greek strawberry tree) may be a vicariant pair, as it is isolated geographically from other Arbutus species (Torres et al., 2002; Blondel et al., 2010). A. unedo is used and $A$. andrachne has the potential for use as an ornamental shrub in the urban and suburban landscape (Bertsouklis and Papafotiou, 2013), while both are recommended species for reforestations in Mediterranean region, where fires are common, as they are characterized by vigorous re-sprouting after fire and overgrazing (Konstantinidis et al., 2006; Moreno-Jiménez, 2008; Kazanis et al., 2012). They both have high medicinal value (Diba et al., 2010; González et al., 2010; Afifi-Yazar et al., 2011; Mendes et al., 2011; Etxeberria et al., 2012; Abidi et al., 2015; Güler et al., 2015), while strawberry tree fruits are an excellent source of vitamin C, dietary fiber and total available carbohydrates, sugars, potassium and secondary metabolites, such as phenolic compounds, being poor in lipids and $\mathrm{Na}$, with ascorbic acid and fat-soluble antioxidants (Ruiz-Rodríguez, 2011; Mosele et al., 2016) of higher values than other red small fruits (Guerreiro et al., 2013). They are also used for preparing liqueurs and aromatic traditional distillate (Soufleros et al., 2005; González et al., 2011; Botelho et al., 2015). Strawberry tree fruits can be stored at low temperature preserving their quality (Guerreiro et al., 2013; Fadda et al., 2015) and they could be introduced in the market as fruits and/ or as a source of bioactive compounds for dietary supplements or functional foods used as components in yoghurts, in cereal bars, in pastry making and confectionery, as flavors or in pieces, like other berries (Ayaz et al., 2000; Alarcão-e-Silva et al., 2001; Miguel et al., 2014).

A. $\times$ andrachnoides Link is also native of the eastern Mediterranean region including Greece (Arabatzis, 2001; Torres et al., 2002), it is considered a natural hybrid form between $A$. unedo and $A$. andrachne and it is very difficult to distinguish from $A$. andrachne (Bačić et al., 1992; The European Garden Flora, 1997). Apart from forestry and 
424

landscape use it is recommended particularly for cut foliage production because its growth speed is higher than the other two species, has lower production of flowers and fruits and prolonged (90-d) vase life (Cervelli et al., 2012).

Individuals with intermediate morphological characteristics are not necessarily hybrids. Morphological traits in combination with molecular markers (RAPDs) are used to assess genetic variability in plant species or to identify hybrids (Yüzbaşıŏlu et al., 2008; Hrs̆̉ak et al., 2011; Ferreyra et al., 2013; Song et al., 2015). In recent years RAPD have been used for studies between different $A$. unedo genotypes (Takhrouni and Boussaid, 2010; Lopes et al., 2012; Gomes et al., 2013). There are also a few references on morphological traits used for diversity studies in $A$. unedo in Italy (Mulas et al., 1998), Turkey (Celikel et al., 2008) and Portugal (Lopes et al., 2012). Koukos et al. (2015) studied the surface microscalpture and waxes of Greek $A$. unedo and $A$. andrachne, this being the only information on genetic diversity of Greek Arbutus spp.

The objective of the present study was to test both morphological traits (quantitative and qualitative) and molecular markers in order to develop a set of proper descriptors to identify and distinguish Arbutus species found in Greece. The results could be used both for conservation strategies and cultivation of specific genotypes with particular characteristics.

\section{Materials and Methods}

Sampling areas and protocol for sampleplants selection

Individuals, representatives of the two Arbutus species, $A$. unedo and $A$. andrachne, as well as individuals with intermediate characteristics, were sampled for identification in the years 2011-2013 (monthly recordings from October to May), at two typical macchia forests of the prefecture of Attica, Greece, one in Kalamos and another in Varympompi, at 450 and $400 \mathrm{~m}$ altitude, respectively. In macchia forests of Greece $A$. unedo and $A$. andrachne are found mixed, in large populations, while individuals with intermediate characteristics believed to be their natural hybrid $A . \times$ andrachnoides are randomly occurring between these parental species. In each forest a sampling area of about $2 \mathrm{~km}^{2}$ was selected. The geographic coordinates (vertices of a quadrangle) of the Kalamos sampling area were: $38^{\circ} 1604.2^{\prime \prime} \mathrm{N}-23^{\circ} 51^{\prime} 46.9^{\prime \prime} \mathrm{E}$, $38^{\circ} 15^{\prime} 50.8^{\prime \prime} \mathrm{N}-23^{\circ} 51^{\prime} 43.1^{\prime \prime} \mathrm{E}, 38^{\circ} 15^{\prime} 52.7^{\prime \prime} \mathrm{N}, 23^{\circ} 52^{\prime} 07.1^{\prime \prime} \mathrm{E}$, $38^{\circ} 16^{\prime} 09.6^{\prime \prime} \mathrm{N}-23^{\circ} 52^{\prime} 14.4^{\prime \prime} \mathrm{E}$ and those of the Varympompi were: $38^{\circ} 08^{\prime} 02.5^{\prime \prime} \mathrm{N}-23^{\circ} 47^{\prime} 48.9^{\prime \prime} \mathrm{E}, \quad 38^{\circ} 08^{\prime} 13.9^{\prime \prime} \mathrm{N}$ $23^{\circ} 47^{\prime} 58.3^{\prime \prime} \mathrm{E}, 38^{\circ} 08^{\prime} 30.5^{\prime \prime} \mathrm{N}-23^{\circ} 47^{\prime} 43.0^{\prime \prime} \mathrm{E}, 38^{\circ} 08^{\prime} 07.4^{\prime \prime} \mathrm{N}$ $23^{\circ} 47^{\prime} 36.5^{\prime \prime} \mathrm{E}$.

In each area five $A$. unedo and five $A$. andrachne shrubs, as well as four shrubs with intermediate characteristics were selected being 2-3 $\mathrm{m}$ in height and 2-3 $\mathrm{m}$ in diameter (at 150 $\mathrm{cm}$ from the ground). The shrubs were re-sprouted after fires that occurred in 1990 at Kalamos and 1986 in Varympompi. The selected shrubs were at least $100 \mathrm{~m}$ apart from each other and were found along the existing paths (five - six paths) of each sampling area at 0-50 m distance left and right of the path.

\section{Phenotypic classification to three groups}

The identification of the sampled individuals was followed by the classification into three groups including individuals with typical morphological characteristics of $A$. andrachne (Kalamos: no 1-5, code $A_{1-5}$ K, Varympompi: no 6-10, code $A_{1-5} V$ ), individuals with typical morphological characteristics of $A$. unedo (Kalamos: no 11-15, code $\mathrm{U}_{1-5} \mathrm{~K}$, Varympompi: no 16-20, code $\left.U_{1-5} \mathrm{~V}\right)$, and individuals with intermediate phenotype (Kalamos: no 21-24, code $\mathrm{H}_{14} \mathrm{~K}$, Varympompi: no 25-28, code $\mathrm{H}_{14} \mathrm{~V}$ ), which were assigned to the hybrid group (H).

\section{Morphological traits}

A total of 27 morphological traits of crown, leaf, flower and fruit were recorded for each individual; 23 qualitative descriptors (1-23) and five quantitative (24-27) were used (Table I) based on descriptors used for other woody plant species including those used by Lopes et al. (2012) for $A$. unedo. Hundred leaves from each individual (10 replications of 10 leaves each) were used to estimate length/width and leaf area (LI-3100 scanner, LI-COR Biosciences, USA). Mature, fully expanded leaves derived from nodes six to nine, of one year old shoots $(15 \mathrm{~cm}$ length) were selected in early November from the SE-side of the shrubs. Hundred mature fruits derived from each individual were used to estimate fruit diameter. For 24 to 27 characteristics took place customization of characteristics (values 1,2,3).

\section{DNA extraction}

Young leaves were collected in early May from each individual, transported in dry ice and stored at $-80{ }^{\circ} \mathrm{C}$. Genomic DNA was extracted from $0.1 \mathrm{~g}$ of leaves using the Dneasy Plant Mini Kit (Qiagen). Amplification reactions were performed according to Stavrakakis and Biniari (1998), using the same PCR apparatus. Fifteen 10-mer oligonucleotide arbitrary primers were used (Table 2) for the amplification of RAPD sequences out of which 12 primers that could generate discernible and reproducible bands was selected for formal amplification. All reactions were repeated at least twice with independently isolated genomic DNA as templates.

\section{Gel electrophoresis}

Aliquots $(20 \mu \mathrm{l})$ of the RAPD products were analyzed in $2 \%$ agarose gel electrophoresis in TAE buffer $(40 \mathrm{mM}$ Trisacetate and $1 \mathrm{mM}$ EDTA, $\mathrm{pH} 8)$. After staining in ethidium bromide $\left(1 \mu \mathrm{g} \mathrm{ml}^{-1}\right)$ the gels were photographed on a Gel Doc 1000 (Biorad). A mix of $\lambda$ DNA Hind III $\times$ Hae III was used as size marker. All of the reactions were repeated at least twice with independently isolated genomic DNA as templates.

\section{Data analysis}

The matrix of average taxonomic distance for individuals was computed using the Euclidean distance coefficient. Cluster analysis was conducted on the taxonomic distance matrix with the Unweighted Pair Group Method based on Arithmetic Average (UPGMA) and the dendrograms were generated based on the genetic distance matrix. One-way ANOVA was used for determination of the differences between the mean values of the leaf traits. Genetic similarities were calculated using the Simple Match (SM) and Jaccard (JAC) coefficients described by Sokal and Sneath (1963). The RAPD data were used to generate two genetic distance matrices and dendrograms were generated using the same methods used with the morphologic data. 
Principal coordinate analysis (PCA) was used in order to verify cluster analysis and to assist in visualizing the data. Mantel test (Mantel, 1967) was used to estimate the correlation between the distance matrices resulting from morphological, RAPD and combined analyses. Statistical analysis of morphological and RAPD markers was conducted by the software NTSYS-pc version 2.11f (Rolf, 1992).

\section{Results and Discussion}

\section{Morphological characteristics}

In the two study areas a few individuals with a mixture of intermediate morphological characteristics between $A$. unedo and $A$. andrachne were found, resembling more to $A$. andrachne. The distinction was mainly based on the morphology of the bark that was smooth and cinnamon-red in color, peeling in small strips, every year, with high rate, revealing a grey-green internal like the bark of $A$. andrachne, with the difference that $A$. andrachne bark was peeling in long strips (Table I). The bark of $A$. unedo was totally different being rough, ash-grey and occasionally peeling in small flakes revealing a chestnut-colored internal; $A$. unedo individuals were strong branching from base in contrary to other individuals.

The leaves of plants with intermediate morphological characteristics were leathery and elastic, shiny, with dark green colour on the upper side, like $A$. andrachne leaves; $A$. unedo leaves were membranaceous-rough, not shiny with green colour of upper side. Intermediate individuals had serrate leaves similar to $A$. unedo and their shape was either like $A$. unedo (elliptical to obovate) or $A$. andrachne (elliptical to oblong lanceolate). Petiole length and fruit diameter of intermediate individuals were also counted between $A$. andrachne and $A$. unedo. These characteristics of plants with intermediate characteristics match with descriptions of $A . \times$ andrachnoides the natural hybrid between A. andrachne and A. unedo (Arabatzis, 2001).

It was also observed that the flowering period of intermediate individuals was either like $A$. andrachne (January-April) or like $A$. unedo (October-January). Fruiting time was the same (OctoberJanuary) in all species. Fruits of intermediate individuals were spherical, red-orange, with slightly granular surface like $A$. andrachne in contrast to granular surface of $A$. unedo. Fruit taste of intermediate individuals was sweet, like $A$. unedo, while $A$. andrachne was astringent.

Leaves of $A$. andrachne were larger than those of individuals with intermediate characteristics and $A$. unedo leaves were the smallest of all. Locality did not affect leaf length and leaf area (Table 3). Principal coordinate analysis confirmed the results and four components have been arranged in a decline series of their importance, explaining $98.92 \%$ of the total variability among the different individuals. All suggested descriptors (Table 1) that are involved in the same principal component are strong correlated. Descriptors 2 (vegetation density), 4 (branching), 5 (bark surface), 6 (external bark colour), 7 (bark peeling), 8 (peeling time), 9 (peeling rate), 10 (internal bark colour), 12 (leaf texture), 13 (boat-shaped leave), 16 (leaf colour of upper side), 21 (fruit surface) and 27 (fruit diameter) contributed better to variability compared to descriptors 17 (flowering) or 26 (fruit diameter); qualitative characteristics were strong correlated while quantitative characteristics were found to be more variable (Table 4, Fig. 1).

Cluster analysis separated the individuals according to their morphological characteristics in three branches; individuals $\mathrm{H}$ were found to be distinct from A or U but closer to A (Fig. 2) and the Mantel test comparing Euclidean values matrix and cophenetic matrix gave very high value $(\mathrm{r}=0.965)$. The analysis of the above data indicated that most probably the individuals with intermediate characteristics are the hybrid form $A . \times$ andrachnoides.

Table 1. Morphological traits of Arbutus individuals

\begin{tabular}{|c|c|c|c|c|}
\hline Code & Morphological Trait (descriptor) & & code-descriptor state & \\
\hline 1 & Growth Habit & 1. Shrub & 2: Tree & \\
\hline 2 & Vegetation Density & 1: Medium & 2: Strong & \\
\hline 3 & Regeneration after pruning & 1: High & 2: Little & \\
\hline 4 & Branching from base & 1: Medium & 2: Strong & 3: Very strong \\
\hline 5 & Bark surface & 1: Smooth & 2: Rough & \\
\hline 6 & Bark colour (external) & 1: Cinnamon-red & 2: Ash-grey & \\
\hline 7 & Bark peeling in & 1: Long strips & 2: Short strips & 3: Small flakes \\
\hline 8 & Peeling every year & 1: Yes & 2: No & \\
\hline 9 & Peeling rate & 1: High & 2: Low & \\
\hline 10 & Bark colour (internal) & 1: Grey-green & 2: Chestnut & \\
\hline 11 & Leaf persistency & 1: Evergreen & 2: Deciduous & \\
\hline 12 & Leaf texture & 1: Leathery-elastic & 2: Membranaceous-tough & \\
\hline 13 & Boat-shaped leave & 1: Yes & 2: No & \\
\hline 14 & Leaf shape & 1: Elliptical to oblong lanceolate & 2: Elliptical to obovate & 3: Intermediate \\
\hline 15 & Leaf margin & 1: Entire & 2: Serrate & 3: Lightly serrate \\
\hline 16 & Leaf colour of upper side & 1: Green & 2: Light green & \\
\hline 17 & Flowering & 1: October-January & 2: January-April & \\
\hline 18 & Flower colour & 1: White-greenish & 2: Other & \\
\hline 19 & Fruiting & 1: October-January & 2: Other & \\
\hline 20 & Fruit shape & 1: Spherical & 2: Elliptical & \\
\hline 21 & Fruit surface & 1: Granular & 2: Lightly granular & \\
\hline 22 & Fruit colour & 1: Orange - red & 2: Other & \\
\hline 23 & Fruit taste & 1: Sweet & 2: Astringent & \\
\hline 24 & Leaf ratio $(\mathrm{x} / \mathrm{y})(\mathrm{cm})$ & $1: 1.32-1.78$ & $2: 1.78-2.24$ & $3: 2.24-2.70$ \\
\hline 25 & Leaf surface $\left(\mathrm{cm}^{2}\right)$ & $1: 10.30-15.00$ & $2: 15.10-19.80$ & $3: 19.90-24.60$ \\
\hline 26 & Petiole length $(\mathrm{cm})$ & $1: 0-1$ & $2: 1-2$ & $3: 2-3$ \\
\hline 27 & Fruit diameter $(\mathrm{cm})$ & $1: 1.10-1.40$ & $2: 1.40-1.90$ & 3: $1.90-2.90$ \\
\hline
\end{tabular}


Table 2. Primer sequences, number of bands per primer, number of polymorphic bands per primer and the approximate band size range

\begin{tabular}{ccccc}
\hline Primer & $\begin{array}{c}\text { Nucleotide Sequence } \\
\left(5^{\prime} \text { to 3') }\right.\end{array}$ & $\begin{array}{c}\text { No. } \\
\text { of bands }\end{array}$ & $\begin{array}{c}\text { No. of polymorphic } \\
\text { bands }\end{array}$ & $\begin{array}{c}\text { Percentage of polymorphic } \\
\text { bands (\%) }\end{array}$ \\
\hline $1224^{*}$ & CAGGCCCTTC & 15 & 10 & 66.67 \\
$1225^{*}$ & AGGTGACCGT & 9 & 6 & 66.67 \\
$1226^{*}$ & CGCAGGATGG & 8 & 4 & 50.00 \\
$127^{*}$ & GTGTGCCCCA & 11 & 4 & 36.36 \\
OPF-01 & ACGGATCCTG & 21 & 12 & 57.14 \\
OPF-02 & GAGGATCCCT & 17 & 12 & 70.58 \\
OPF-03 & CCTGATCACC & 16 & 10 & 62.50 \\
OPF-04 & GGTGATCAGG & 16 & 9 & 68.75 \\
OPF-06 & GGGAATTCGG & 13 & 69.23 \\
OPM-11 & GTCCACTGTG & 12 & 6 & 50.00 \\
OPM-14 & AGGGTCGTTC & 7 & 5 & 71.43 \\
\hline OPM-18 & CACCATCCGT & 21 & 16 & 76.19 \\
\hline
\end{tabular}

${ }^{*}$ Primers were obtained from IBBM (University of Crete, Greece)

\begin{tabular}{|c|c|c|c|c|c|c|c|}
\hline \multirow{2}{*}{ Trait (Leaf) } & \multirow{2}{*}{ Source } & \multirow{2}{*}{$\begin{array}{c}F \\
(p=0.05)\end{array}$} & \multicolumn{3}{|c|}{ Species $(S)$} & \multicolumn{2}{|c|}{ Locality (L) } \\
\hline & & & $\mathrm{A}$ & $\mathrm{H}$ & $\mathrm{U}$ & $\mathrm{K}$ & $\mathrm{V}$ \\
\hline \multirow{3}{*}{$\begin{array}{l}\text { Length } \\
(\mathrm{cm})\end{array}$} & $\mathrm{L}$ & NS & \multirow{3}{*}{$6.4 \mathrm{~b}$} & \multirow{3}{*}{$6.7 \mathrm{a}$} & \multirow{3}{*}{$6.3 \mathrm{~b}$} & \multirow{3}{*}{$6.5 \mathrm{a}$} & \multirow{3}{*}{$6.4 \mathrm{a}$} \\
\hline & $S$ & * & & & & & \\
\hline & $\mathrm{LxS}$ & NS & & & & & \\
\hline \multirow{3}{*}{$\begin{array}{l}\text { Width } \\
(\mathrm{cm})\end{array}$} & $\mathrm{L}$ & NS & \multirow{3}{*}{$4.2 \mathrm{a}$} & \multirow{3}{*}{$3.2 \mathrm{~b}$} & \multirow{3}{*}{$2.8 \mathrm{c}$} & \multirow{3}{*}{$3.4 \mathrm{a}$} & \multirow{3}{*}{$3.4 \mathrm{a}$} \\
\hline & $S$ & $*$ & & & & & \\
\hline & $\mathrm{Lx} S$ & $*$ & & & & & \\
\hline \multirow{3}{*}{ Length/Width } & $\mathrm{L}$ & NS & \multirow{3}{*}{$1.5 \mathrm{c}$} & \multirow{3}{*}{$2.1 \mathrm{~b}$} & \multirow{3}{*}{$2.3 \mathrm{a}$} & \multirow{3}{*}{$2.0 \mathrm{a}$} & \multirow{3}{*}{$2.0 \mathrm{a}$} \\
\hline & S & $*$ & & & & & \\
\hline & $\mathrm{LxS}$ & * & & & & & \\
\hline \multirow{3}{*}{$\begin{array}{l}\text { Area } \\
\left(\mathrm{cm}^{2}\right)\end{array}$} & $\mathrm{L}$ & NS & \multirow{3}{*}{$215.5 \mathrm{a}$} & \multirow{3}{*}{$159.4 \mathrm{~b}$} & \multirow{3}{*}{$125.7 \mathrm{c}$} & \multirow{3}{*}{$163.2 \mathrm{a}$} & \multirow{3}{*}{$170.6 \mathrm{a}$} \\
\hline & $S$ & $*$ & & & & & \\
\hline & $\mathrm{L} \times \mathrm{S}$ & NS & & & & & \\
\hline
\end{tabular}

A: A. andrachne; $\mathrm{H}$ : Intermediate individuals; $\mathrm{U}:$ A. unedo; $\mathrm{K}:$ Kalamos, V: Varympompi

${ }^{*} \mathrm{p}<0.05$, NS: $\mathrm{p}>0.05$. Values followed by different lowercase letter within each trait are significantly different at the $5 \%$ level, determined by the one-way Anova
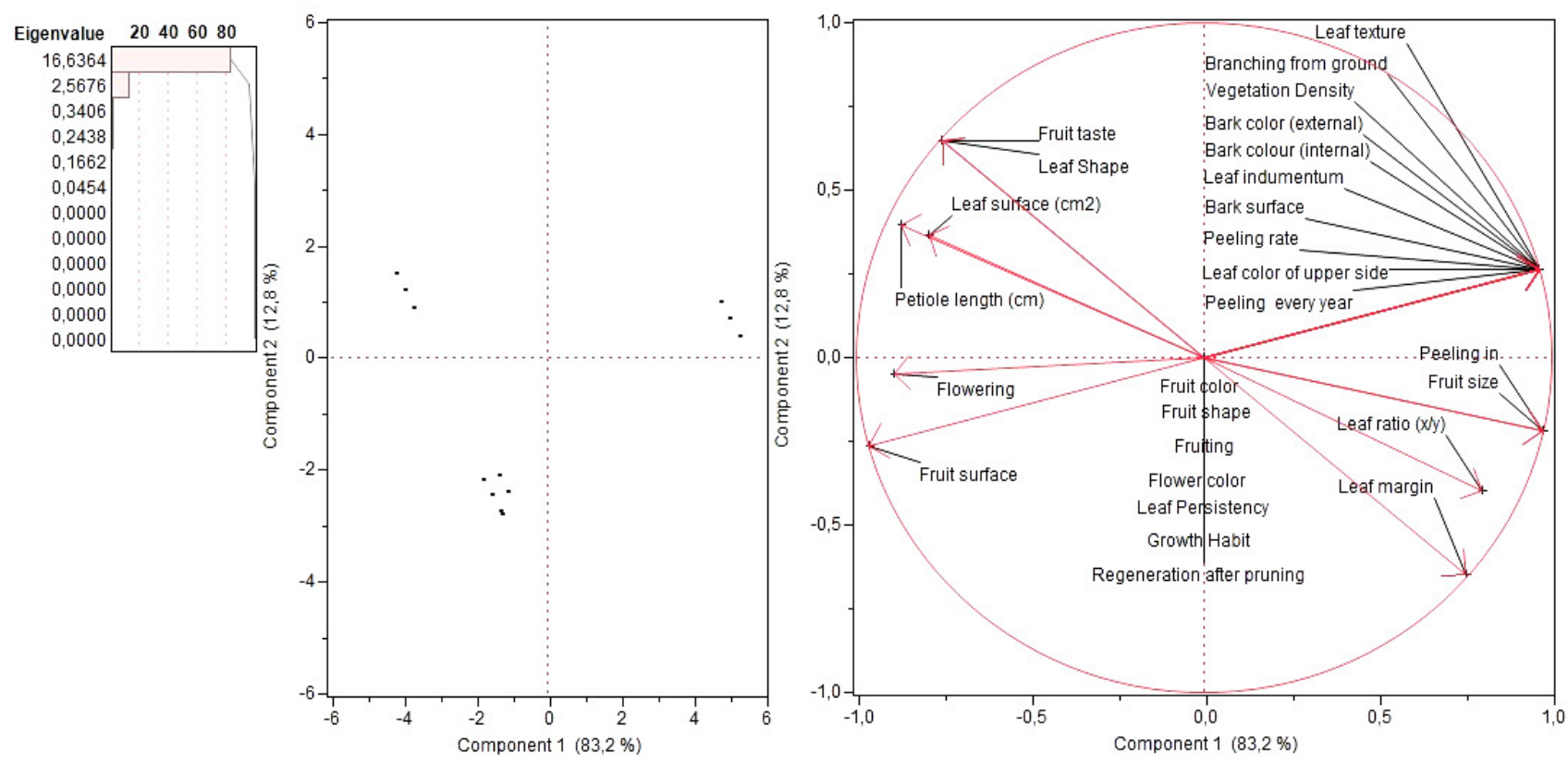

Fig. 1. Evaluation of the descriptors and their contribution to the variability of the individuals studied

\section{Molecular analysis}

For the molecular analysis and the identification of the individuals studied, 12 primers were used which proved to be highly polymorphic (63.5\% polymorphism) producing a total of 166 amplified markers. Higher percentage of polymorphism was presented by primers OPM-18 and OPM14 (76.19\% and $71.43 \%$ respectively, Table 2). Primers could classified in three groups (Table 2) with: 
Table 4. Evaluation of the descriptors and their contribution to the variability of the individuals studied

\begin{tabular}{|c|c|c|c|}
\hline \multicolumn{4}{|c|}{ Principal Components } \\
\hline 1 & 2 & 3 & 4 \\
\hline \multicolumn{4}{|c|}{ \% Contribution to variability } \\
\hline 83.18 & 12.83 & 1.7 & 1.21 \\
\hline \multicolumn{4}{|c|}{ Eigenvalue } \\
\hline 16.63 & 2.57 & 0.34 & 0.24 \\
\hline \multicolumn{4}{|c|}{ Related Descriptors } \\
\hline 2 & 14 & 24 & 17 \\
\hline 4 & 15 & 25 & 26 \\
\hline 5 & 23 & & \\
\hline \multicolumn{4}{|l|}{6} \\
\hline \multicolumn{4}{|l|}{7} \\
\hline \multicolumn{4}{|l|}{8} \\
\hline \multicolumn{4}{|l|}{9} \\
\hline \multicolumn{4}{|l|}{10} \\
\hline \multicolumn{4}{|l|}{12} \\
\hline \multicolumn{4}{|l|}{13} \\
\hline \multicolumn{4}{|l|}{16} \\
\hline \multicolumn{4}{|l|}{21} \\
\hline 27 & & & \\
\hline
\end{tabular}

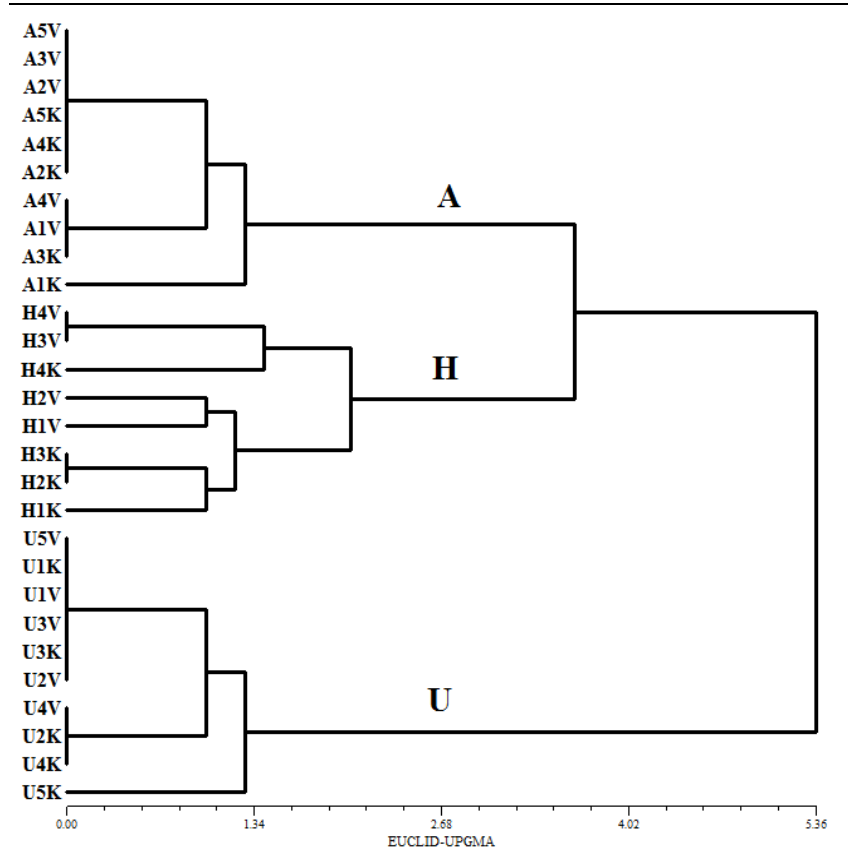

Fig. 2. UPGMA dendrogram of 28 Arbutus individuals based on Euclidean distance of morphological character analysis. Individual names: $\mathrm{A}:$ A andrachne, $\mathrm{U}:$ A. unedo, $\mathrm{H}$ :Arbutus spp. with intermediate morphological characteristics, K:Kalamos, V:Varympompi, 1-5:number of individual

a) high polymorphic ability (more than 15 bands: 1224 , OPF-01, OPF-02, OPF-03, OPF-04, OPM-18). Primers OPF-01, OPF-02 and OPM-18 were suitable to identify individuals of $A$. unedo;

b) medium polymorphic ability (10-15 bands: primers 1227 , OPF-06, OPM-11). Primer OPF-06 was suitable to identify $A$. andrachne individuals;

c) low polymorphic ability (7-10 bands, primers 1225,1226 , OPM-14). Primers OPM-14 and 1225 were suitable to identify $A$. unedo individuals.

The primers 1225 and 1227 proved much more useful in differentiating individuals as they generated more polymorphic DNA fragments. As expected there was genetic variation

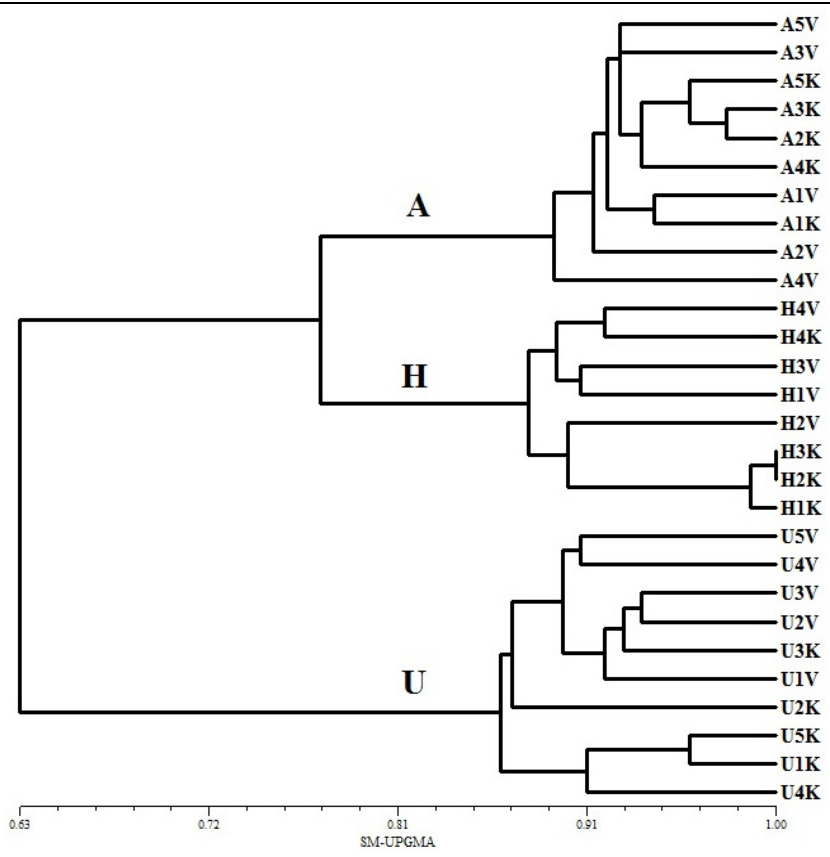

Fig. 3. UPGMA dendrogram of 28 Arbutus individuals based on RAPD molecular analysis for SM, showing genetic similarity between individuals studied. Individual names: A: $A$. andrachne, $\mathrm{U}:$ A. unedo, $\mathrm{H}$ :Arbutus spp. with intermediate morphological characteristics, K:Kalamos, V:Varympompi, 15: number of individual

among the individuals studied and they were grouped in three different branches (Fig. 3, 4) consistently with our observations based on morphological characteristics.

Individuals with intermediate morphological characteristics from Kalamos ( $\mathrm{I}=0.98-1.00)$ grouped in one branch, something that allows the hypothesis that belong to another species, at least for the primers that were used, possibly $A$. $\times$ andrachnoides (Fig 1). The genetic similarity between $A$. andrachne individuals from two different sampling areas was high $(I=0.94)$. The higher genetic similarity found between individuals with intermediate characteristics and $A$. andrachne individuals $(\mathrm{I}=0.69-0.73)$ was consistent with the bigger 


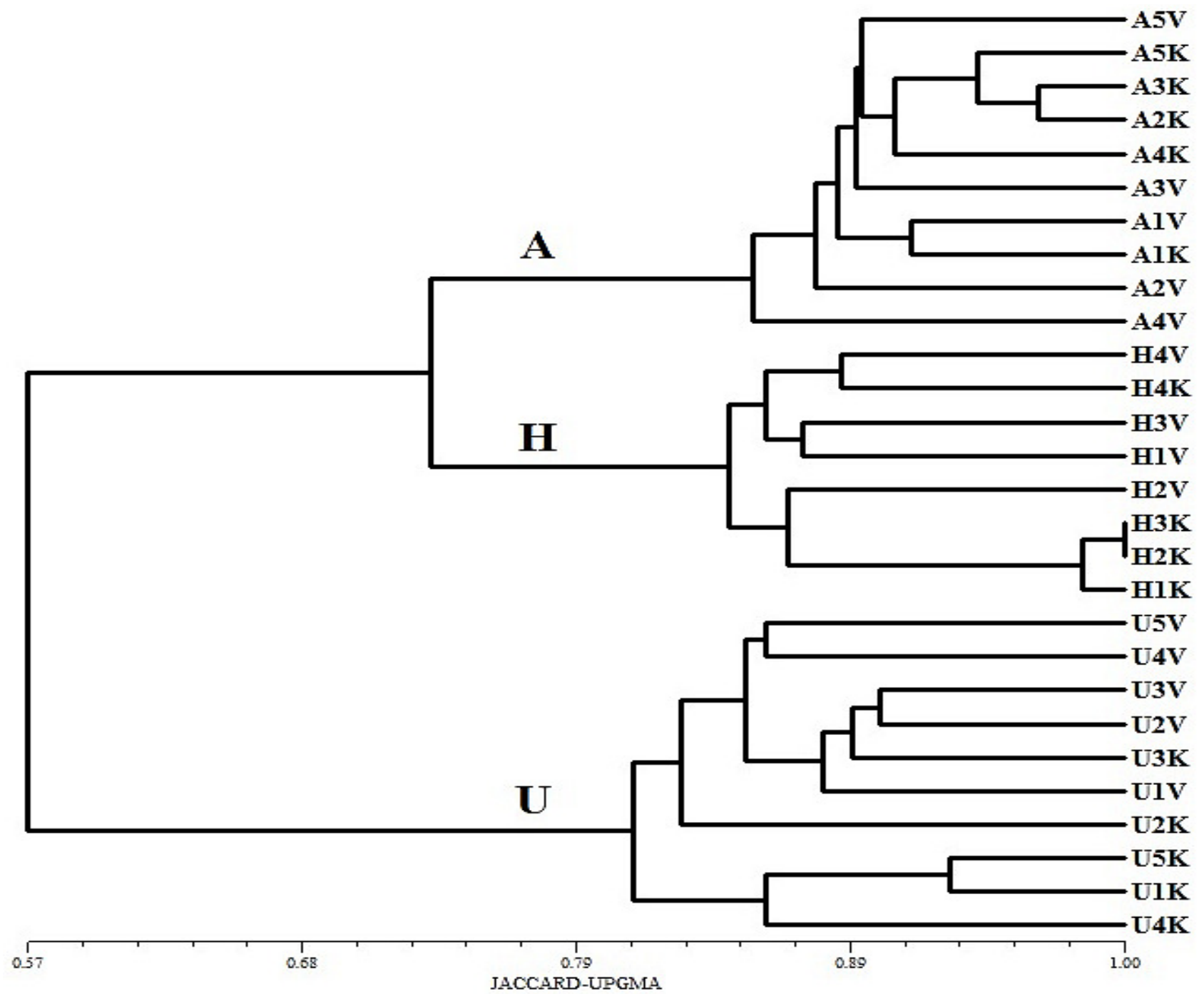

Fig. 4. UPGMA dendrogram of 28 Arbutus individuals based on RAPD molecular analysis Jaccard, showing genetic similarity between individuals studied. Individual names: A:A. andrachne, U:A. unedo, $\mathrm{H}:$ Arbutus spp. with intermediate morphological characteristics, K:Kalamos, V:Varympompi, 1-5:number of individual

phenotypic resemblance between these two species. On the contrary genetic similarity between $A$. unedo individuals and individuals with intermediate characteristics was lower (I=0.52-0.60), consistently with their lower phenotypic resemblance. Low degree of polymorphism was observed in each species population and differentiation among populations was not related to geographical distance similar to Takrouni and Boussaid, (2010) and Gomes et al. (2013), while moderate differentiation was recorded between or within $A$. unedo populations in Portugal Lopes et al. (2012).

Association between matrices of morphological and genetic distances were investigated (Mantel test) and the results of the tests showed significant correlation $(\mathrm{r}=0.958$ and $\mathrm{r}=0.951$ for SM and JAC, respectively).

Thus, individuals sampled as $A . \times$ andrachnoides showed both a mixture of $A$. andrachne and $A$. unedo morphological characteristics and intermediate characteristics that complicated their identification as hybrids. However the suggested descriptors in combination with molecular markers proved a useful tool to assess the hybrid identity of these individuals. Combination of morphological traits with RAPD has been successfully used for differentiation of other natural hybrids and clones, too (Yüzbaşıŏlu et al., 2008; Stavrakaki and Biniari, 2016). The results of this research are supported by the fact that plants derived by micropropagation of individuals with intermediate characteristics defined as $A$. $\times$ andrachnoides (Bertsouklis and Papafotiou, 2011) were morphologically identical after three years ex vitro growth to the mother plant found in Kalamos (unpublished data) revealing that the hybrid was defined correctly.

A total of morphological characteristics that proved for first time suitable for identification of the hybrid form of the two Greek Arbutus species, RAPD profiles, the resulting similarity and the dendrogram, led to the conclusion that most probably individuals with intermediate morphological characteristics from Kalamos is another species, possibly the one reported in the bibliography as a natural hybrid between $A$. unedo and $A$. andrachne, named $A . \times$ andrachnoides. All three Arbutus species found in Greece have or could be introduced for various uses in forestry, landscape, medicinal and horticultural 
industry, as mentioned in the introduction section. Furthermore the in vitro propagation of these species has been successfully achieved both by axillary bud proliferation of adult plant (Mereti et al., 2002; Bertsouklis and Papafotiou, 2009; Gomes et al., 2010; Mohamed El-Sayed et al., 2010; Bertsouklis and Papafotiou, 2011) and from seedlings (Papafotiou et al., 2013), so the most suitable clones could be propagated. All these techniques would be very useful tools for breeding programs involving Arbutus species or for developing effective conservation strategies. Santiso et al. (2015) reported that $A$. unedo maintains the ability to evolve despite low genetic differentiation and stabilizing selection. The present study, proposing appropriate morphological characteristics in combination with selected molecular markers for distinguish individuals of three Arbutus species, is a step in achieving these goals for Arbutus spp. in Greece and other counties, particularly those in which Arbutus species are endangered or threatened, as A. andrachne in Ukraine, Albania, Jordan and Georgian SSR (Al-Tellawi, 1989; Garzuglia, 2006; Melia et al., 2012), $A$. unedo in Slovenia (Garzuglia, 2006) and $A . \times$ andrachnoides in Croatia (Šatović, 2004).

\section{Conclusions}

The present work provides both morphological traits and molecular markers (RAPD) to differentiate the three Arbutus species found in Greece, particularly useful for identification of the hybrid $A$. $\times$ andrachnoides from the parental species $A$. andrachne and $A$. unedo, and in this way to facilitate their exploitation in horticultural and pharmaceutical industry. The applied morphometric characteristics are suggested as a basis to develop a complete list of discriminating descriptors for Arbutus genus.

\section{References}

Abidi E, Habib J, Yassine A, Chahine A, Mahjoub T, Elkak A (2015). Effects of methanol extracts from roots, leaves, and fruits of the Lebanese strawberry tree (Arbutus andrachne) on cardiac function together with their antioxidant activity. Pharmaceutical Biology 54(6):1035-1041.

Afifi-Yazar FU, Kasabri V, Abu-Dahab R (2011). Medicinal plants from Jordan in the treatment of cancer: traditional uses vs. in vitro and in vivo evaluations, Part 1.Planta Medica 77:1203-1209.

Al-Tellawi A (1989). Forests in Jordan. Dar Al-Bashir, Amman, Jordan.

Alarcão-E-Silva MLCMM, Leitão AEB, Azinheira HG, Leitão MCA (2001). The Arbutus berry: Studies on its color and chemical characteristics at two mature stages. Journal of Food Composition and Analysis 14(1):27-35.

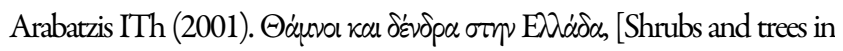
Greece].Ecological Union of Drama, T.E.I. of Kavala, Drama, Greece.

Ayaz FA, Kucukislamoglu M, Reunanen M (2000). Sugar, non-volatile and phenolic acids composition of strawberry tree (Arbutus unedo L. var. ellipsoidea) fruits. Journal of Food Composition and Analysis 13(2):171-177.

Bačić T, Lawrence TJ, Cutler DF (1992). Leaf Anatomy of an Arbutus Taxon from Yugoslavia. Kew Bulletin 47(3):535-543.
Bertsouklis KF, Papafotiou M (2009). In vitro propagation of Arbutus andrachne L. Acta Horticulturae 813:477-480.

Bertsouklis KF, Papafotiou M (2011). Effect of various cytokines on micropropagation of Arbutus $\times$ andrachnoides Link. Acta Horticulturae 923:213-218.

Bertsouklis KF, Papafotiou M (2013). Seed germination of Arbutus unedo, A. andrachne and their natural hybrid $A$. andrachnoides in relation to temperature and period of storage. HortScience 48(3):347-351.

Blondel J, Aronson J, Bodiou Y, Boeuf G (2010). The Mediterranean Region: Biological Diversity in Space and Time. Oxford University Press, Oxford, New York.

Botelho G, Gomes F, Ferreira FM, Caldeira I (2015). Influence of maturation degree of Arbutus (Arbutus unedo L.) fruits in spirit composition and quality. International Journal of Biological, Biomolecular, Agricultural, Food and Biotechnological Engineering 9(6): 478-483.

Celikel G, Demirsoy L, Demirsoy H (2008). The strawberry tree (Arbutus unedo L.) selection in Turkey. Scientia Horticulturae 118(2):115-119.

Cervelli C, Farina E, Dalla Guda C, Giovannini A, Liotta A, Paterniani T, ... Aprile S (2012). Development of new ornamental plants and germaplasm selection in Mediterranean native species. Acta Horticulturae 937:45-50.

Diba MA, PaoliniJ, Bendahou M, Varesi L, Allali H, Desjobert JM, Tabti B, Costa J (2010). Chemical composition of fatty acid and unsaponifiable fractions of leaves, stems and roots of Arbutus unedo and in vitro antimicrobial activity of unsaponifiable extracts. Natural Product Communications 5(7):1085-1090.

Etxeberria U, de la Garza AL, Campion J, Martinez JA, Milagro FI (2012). Antidiabetic effects of natural plant extracts via inhibition of carbohydrate hydrolysis enzymes with emphasis on pancreatic alpha amylase. Expert Opinion on Therapeutic Targets, 16(3):269-297.

Fadda C, Fenu PMA, Usai G, Del Caro A, Diez YM, Sanguinetti AM, Pig A (2015). Antioxidant activity and sensory changes of strawberry tree fruits during cold storage and shelf life. Czech Journal of Food Sciences 33(6):531-536.

Ferreyra LI, Vilardi JC, Verga A,Lopez V, Saidman BO (2013). Genetic and morphometric markers are able to differentiate three morphotypes belonging to Section Algarobia of genus Prosopis (Leguminosae, Mimosoideae). PlantSystematics and Evolution 299(6):1157-1173.

Garzuglia M (2006). Threatened, endangered and vulnerable tree species: A Comparison between FRA 2005 and the IUCN red list. Working Paper 108/E, FAO, Forestrry Department, Rome, Italy.

Gomes F, Simões M, Lopes ML, Canhoto JM (2010). Effect of plant growth regulators and genotype on the micropropagation of adult trees of Arbutus unedo L. (strawberry tree). New Biotechnology 27(6):882892.

Gomes F, Costa R, Ribeiro M, Figueiredo E, Canhoto JM (2013). Analysis of genetic relationship among Arbutus unedo L. genotypes using RAPD andSSR markers. Journal of Forest Research 24(2):227-236.

González JA, García-Barriuso M, Amich F (2010). Ethnobotanical study of medicinal plants traditionally used in the Arribes del Duero, western Spain. Journal of Ethnopharmacology 131(2):343-355. 
430

González JA, García-Barriuso M, Amich F (2011). The consumption of wild and semi-domesticated edible plants in the Arribes del Duero (Salamanca-Zamora, Spain): an analysis of traditional knowledge. Genetic Resources and Crop Evolution 58(7):991-1006.

Guerreiro AC, Gago CML, Miguel MGC, Antunes MDC (2013). The effect of temperature and film covers on the storage ability of Arbutus unedo L. fresh fruit. Scientia Horticulturae 159:96-102.

Güler B, Manav E, Uğurlu E (2015). Medicinal plants used by traditional healers in Bozüyük (Bilecik-Turkey). Journal of Ethnopharmacology 173:39-47.

Hrš̆ak V, Brava S, Sedlar Z, Pejić I (2011). Morphometric and molecular (RAPD) analysis of six Serapias taxa from Croatia. Biologia 66(1):55-63.

Kazanis D, Xanthopoulos G, Arianoutsou (2012). Understorey fuel load estimation along two post-fire chronosequences of Pinus halepensis Mill. forests in Central Greece. Journal of Forest Research 17(1):105-109.

Konstantinidis P, Tsiourlis G, Xofis P (2006). Effect of fire season, aspect and pre-fire plant size on the growth of Arbutus unedo L. (strawberry tree) resprouts. ForestEcology and Management 225(1-3):359-367.

Koukos D, Meletiou-Christou M-S, Rhizopoulou S (2015). Leaf surface wettability and fatty acid composition of Arbutus unedo and Arbutus andrachne grown under ambient conditions in a natural macchia. Acta Botanica Gallica 162(3):225-232.

Lopes L, Sá O, Pereira JA, Baptista P (2012). Genetic diversity of Portuguese Arbutus unedo L. populations using leaf traits and molecular markers: An approach for conservation purposes. Scientia Horticulturae 142:5767.

Mantel N (1967). The detection of disease clustering and a generalized regression approach. Cancer Research 27:209-220.

Melia N, Gabedava L, Barblishvili T, Jgenti L (2012). Reproductive biology studies towards the conservation of two rare species of Colchic flora, Arbutus andrachne and Osmanthus decorus. Turkish Journal of Botany 36:55-62.

Mendes L, de Freitas V, Baptista P, Carvalho P (2011). Comparative antihemolytic and radical scavenging activities of strawberry tree (Arbutus unedo L.) leaf and fruit. Food and Chemical Toxicology 49(9):2285-2291.

Mereti M, Grigoriadou K, Nanos GD (2002). Micropropagation of the strawberry tree, Arbutus unedo L. Scientia Horticulturae 93(2):143-148.

Miguel MG, Faleiro ML, Guerreiro AC, Antunes MD (2014). Arbutus unedo L.: Chemical and biological properties. Molecules 19(10):1579915823.

Mohamed El-Sayed E-M, Dewir YH, Omar AMK (2010). In vitro propagation of adult strawberry tree (Arbutus unedo L.) through adventitious shoots and somatic embryogenesis. Propagation of Ornamental Plants 10(2):93-98.

Mosele JI, Macià A, Romero MP, Motilva MJ (2016). Stability and metabolism of Arbutus unedo bioactive compounds (phenolics and antioxidants) under in vitro digestion and colonic fermentation. Food Chemistry 201:120-130.

Moreno-Jiménez E, Peñalosa JM, Carpena-Ruiz RO, Esteban E (2008). Comparison of arsenic resistance in Mediterranean woody shrubs used in restoration activities. Chemosphere 71(3):466-473.
Mulas M, Cani MR, Brigaglia N, Deidda P (1998). Varietal selection in wild populations for the cultivation of myrtle and strawberry tree in Sardinia. Rivista di Frutticoltura e di Ortofloricoltura 60(3):45-50

Papafotiou M, Bertsouklis KF, Trigka M (2013). Micropropagation of Arbutus unedo, A. andrachne, and their natural hybrid $A . \times$ andrachnoides, from seedling explants. The Journal of Horticultural Science and Biotechnology 88(6):768-775.

Rohlf FJ (1992). NTSYS/pc: Numerical Taxonomy and Multivariate Analysis System, Version 1.80. Exeter Software, Setauket, New York.

Ruiz-Rodríguez BM, Morales P, Fernández-Ruiz V, Sánchez-Mata MC, Cámara M, Díez-Marqués C, ... Tardio J (2011). Valorization of wild strawberry-tree fruits (Arbutus unedo L.) through nutritional assessment and natural production data. Food Research International 44(5):1244 1253.

Santiso X, López L, Gilbert KJ, Barreiro R, Whitlock MC, Retuerto R (2015). Patterns of genetic variation within and among populations in Arbutus unedo and its relation with selection and evolvability. Perspectives in Plant Ecology, Evolution and Systematics 17(3):185192.

ŠatovićZ (2004). Legal protection, conservation and cultivation of medicinal and aromatic plants in Croatia In: Baričevič D, Bernáth J, Maggioni L, Lipman E (Eds). ECP/GR Report of a Working Group on Medicinal and Aromatic Plants. Rim:IPGRI pp 3438.

Sokal RR, Sneath PH (1963). Principles of Numerical Taxonomy. Freeman WHand Company, San Francisco.

Song Y, Deng M, Hipp AL, Li Q (2015). Leaf morphological evidence of natural hybridization between two oak species (Quercus austrocochinchinensis and Q. kerrii) and its implications for conservation management. European Journal of Forest Research 134(1):139-151.

Soufleros EH, Mygdalia SA, Natskoulis P (2005). Production process and characterization of the traditional Greek fruit distillate "koumaro" by aromatic and mineral composition. Journal of Food Composition and Analysis 18(7):699-716.

Stavrakakis M, Biniari K (1998). Genetic study of grapevine cultivars belonging to the muscat family by random amplified polymorphic DNAmarkers. Vitis 37(3):19-122.

Stavrakaki M, Biniari K (2016). Genotyping and phenotyping of the potential clones, biotypes and variants of grapevine cultivar Korinthiaki Staphis (Vitis vinifera L.).Journal of Agricultural Science 8(3):127-141.

Takrouni MM, Boussaid M (2010). Genetic diversity and population's structure in Tunisian strawberry tree (Arbutus unedo L.). Scientia Horticulturae 126(3):330-337.

The European Garden Flora (1997). In: Cullen J, Knees SG, Cubey HS (Eds).Vol 5. Cambridge University Press, Cambridge, UKpp 485-486.

Torres JA, Valle F, Pinto C, García-Fuentes A, Salazar C, Cano E (2002). Arbutus unedo L. communities in southern Iberian Peninsula mountains. Plant Ecology 160(2):207-223.

YüzbaşıoğluE, Dadandı MY, Özcan (2008). Natural hybridization between Phlomis lycia D. Don $\times$ P. bourgaei Boiss., (Lamiaceae) revealed by RAPD markers. Genetica 133(1):13-20. 